\title{
Comparison of gut microbiota diversity between wild and captive bharals (Pseudois nayaur)
}

\author{
Xiangwen Chi ${ }^{1,2,3}$, Hongmei Gao ${ }^{1,2,3}$, Guosheng Wu ${ }^{4}$, Wen Qin ${ }^{1,2,3}$, Pengfei Song ${ }^{1,2,3}$, Lei Wang ${ }^{1}$, Jiarui Chen ${ }^{1}$, \\ Zhenyuan Cai ${ }^{1,2,3}$ and Tongzuo Zhang ${ }^{1,3^{*}}$
}

\begin{abstract}
Background: Gastrointestinal microbiota play an important role in animal host immunity, nutrient metabolism, and energy acquisition, and have therefore drawn increasing attentions. This study compared the diversity of the gut microbiota of both wild and captive bharals, which is an ungulate herbivore of caprid from the Qinghai-Tibet plateau.

Results: The sequencing of the V4-V5 region of the $16 \mathrm{~S}$ rRNA gene via high-throughput sequencing technology showed that the dominant bacterial phyla are Firmicutes and Bacteroides both in wild and captive bharals. However, their abundance differed significantly between groups. Firmicutes were significantly higher in wild bharals, while Bacteroides were significantly higher in captive bharals. Different diets are likely a key influencing factor in the diversity and abundance of gut microbiota in bharals.

Conclusions: Changes in diets affect the diversity of gut microbiota and the relative abundance of pathogenic bacteria, increasing the risk of diseases outbreak in captive bharals. The results of this study suggest that the structure and function of the gut microbiota should be regulated via dietary intervention, accurate provision of an individualized diet, and optimization of the functional network of gut microbiota and its interaction with the host. This will improve the ex situ protection of wild animals.
\end{abstract}

Keywords: Bharal (Pseudois nayaur), 16S rRNA gene, Gut microbiota, Health assessment, High-throughput sequence analysis

\section{Background}

Due to the use of modern molecular technology, the gut microbiota can be utilized as a signal hub that combines environmental inputs (e.g., diet) with genetic and immune signals. All of this affect the host metabolism, immunity, and infection responses [1], and play an important role in the development of the immune system and in animal health [2-6]. The diversity and abundance of the host intestinal flora are influenced by factors such as species [7], food [8-10], genotype, and age of the host [11]. Further research indicated that changes in the dietary patterns of the host

\footnotetext{
* Correspondence: zhangtz@nwipb.cas.cn

${ }^{1}$ Key Laboratory of Adaptation and Evolution of Plateau Biota, Northwest Institute of Plateau Biology, Chinese Academy of Sciences, No.23 Xinning road, Chengxi district, Xining TN 810008, Qinghai, China

${ }^{3}$ Qinghai Provincial Key Laboratory of Animal Ecological Genomics, No.23

Xinning road, Chengxi district, Xining TN 810008, Qinghai, China

Full list of author information is available at the end of the article
}

can lead to rapid changes in the structure of the microbial community [12], which in turn exerts a profound impact on the health of the host [13]. The role of the diet in the regulation of the composition and metabolic activities of the gut microbiota has been increasingly recognized. Furthermore, the relationship between gut microbiota and animal health has been extensively studied.

The bharal (Pseudois nayaur) is a member of the Artiodactyla, Bovidae, Caprinae, Pseudois, and a national second-class protected animal on the list of key wildlife protection in China [14]. The bharal is mainly distributed throughout the Qinghai-Tibet Plateau and its surrounding areas, including Tibet, Yunnan, Sichuan, Xinjiang, Qinghai, Gansu, Inner Mongolia, Ningxia and Shaanxi [14]. It is one of the large hoofed animals in China and presents the most widely distributed cloven hoofed animal with the largest number on the Qinghai-

(c) The Author(s). 2019 Open Access This article is distributed under the terms of the Creative Commons Attribution 4.0 International License (http://creativecommons.org/licenses/by/4.0/), which permits unrestricted use, distribution, and reproduction in any medium, provided you give appropriate credit to the original author(s) and the source, provide a link to the Creative Commons license, and indicate if changes were made. The Creative Commons Public Domain Dedication waiver (http://creativecommons.org/publicdomain/zero/1.0/) applies to the data made available in this article, unless otherwise stated. 
Tibet Plateau $[15,16]$. The major predator of wild bharals is the snow leopard (Uncia uncia) $[17,18]$, and this predation is important to maintain both the stability of ecosystems and species diversity [15]. At present, research on bharals focuses on population ecology [14, 19], behavioral ecology [20], and system evolution [21, 22]. During winter, bharals often face food shortage, which even lead to death [14]. Therefore, it is very important to study the digestibility and utilization rate of food in bharals. Its gut microbiota exerts a very important influence on this function. Artificial captive protection is an effective means of protection; however, it remains unclear whether the health status of captive bharals will be affected when animals are faced with novel living conditions. Therefore, it is necessary to study the relationship between changes in the gut microbiota and animal health.

This study investigated the composition and structure of the gut microbiota of bharals. The results lead to a better understanding of the digestive mechanism, provide a theoretical basis for the monitoring of abnormal physiological status, control the occurrence of diseases, and optimize the energy conversion rate of the food. The findings provide an important theoretical basis for the research digestive physiology of captive bharals. The results provide information to improve the diet of animals as well as for diagnosis and treatment of intestinal diseases. Furthermore, new research directions are initiated for the development of intestinal microecological agents.

\section{Results}

\section{Sequencing data}

A total of $8,217,442$ high-quality reads were obtained after data quality control, and fecal samples were classified into 3,878 OTUs (operational taxonomic units), 2,443 of which were in the captive group and 3,166 in the wild group.

Rarefaction curves and rank abundance curves are commonly used to describe the diversity of samples within a group. The rarefaction curves directly reflect the rationality of the sequencing data volume, and indirectly reflect the species richness of samples, as shown in Fig. 1a. Since the curves are smooth, a higher data volume would only yield a low number of OTUs, indicating that the volume of sequencing data is sufficiently reasonable. Rank abundance curves provide a visual representation of species richness and sample uniformity. In the horizontal direction, a greater span of the curve indicates a higher species richness, while in the vertical direction, a smoother curve indicates a more homogeneous species distribution [23] (Fig. 1b).

\section{Bacteria composition and relative abundance}

In order to show the relative abundance of bacteria communities more intuitively, we selected the top 10 taxa and generated the relative abundance superposition histogram at phylum and genus level respectively in Fig. 2.

At the phylum level, Firmicutes and Bacteroidetes are the dominant phyla of both wild and captive groups; however, the abundance of Firmicutes (60.35\%) in wild bharals was significantly higher $(P<0.01)$ than that of captive bharals (49.68\%). The abundance of Bacteroides (40.98\%) was significantly higher $(P<0.01)$ in captive bharals than in wild bharals $(31.35 \%)$. In wild and captive groups, the main genera are Bacteroides and Alistipes, and the abundances of Bacteroides and Alistipes in captive bharals were significantly higher $(P<0.05)$ than that in wild bharals.

\section{Analysis of discrepancies between groups}

The goods coverage index exceeded $99 \%$, indicating a high level of diversity coverage in the samples. The observed species, Shannon index, and Simpson index in the wild group were significantly higher than in the captive group $\left(P_{\text {Observed species }}<0.01, P_{\text {Shannon }}<0.01\right.$, and $\left.P_{\text {Simpson }}<0.01\right)$.

To further analyze whether significant differences affected the microbiome structure between the wild and captive group, the multi response permutation procedure (MRPP) significance analysis method was used. The result was $\mathrm{A}=$ $0.1153>0$, indicating that differences between groups were higher than within groups; consequently, the applied study grouping was reasonable and a significant difference $(P=$ 0.001 ) was found between wild and captive groups.

Furthermore, to assess the differences between wild and captive groups, principal component analysis (PCA) (Fig. 3a) and principal coordinates analysis (PCoA) (Fig. 3b) were used. The distance between the points in all graphs reflects the degree of similarity of their respective microbial flora structures. All graphs reflect the obvious difference of samples in each group.

Using the LDA (local-density approximation) Effect Size (LEfSe) analysis method, species with significant differences between groups were selected. The results included three parts: a LDA value distribution histogram, an evolutionary branch diagram (phylogenetic distribution), and an abundance comparison diagram of biomarkers with statistical differences (LDA SCORE $>4$ ) between groups (Fig. 4). According to the LDA scores, biomarkers with statistically significant differences between both groups are listed. The microbial communities that play an important role in each group were identified with the evolutionary branch diagram. In the wild group, Firmicutes, Clostridia, Clostridiales, Ruminococcaceae, Christensenellaceae and Lachnospiraceae are very important. In the captive group, important species are Bacteroidetes, Bacteroidia, Bacteroidales, Rikenellaceae and Alistipes.

\section{Discussion}

At the phylum level, the core microflora of the gut microbiota consisted of Firmicutes and Bacteroides in 

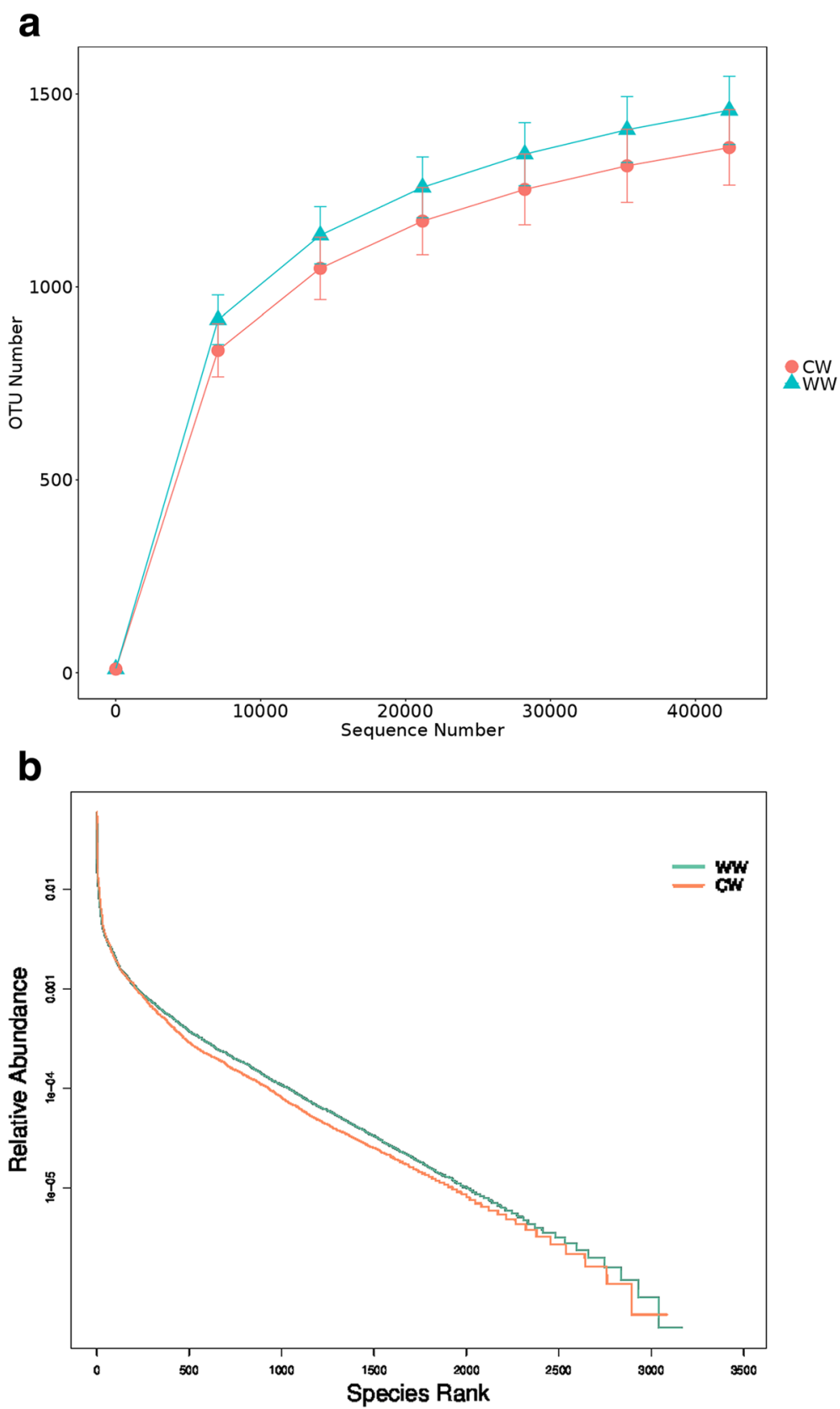

Fig. 1 Rarefaction curves (a) and rank abundance curves (b). CW for captive group, WW for wild group

both captive and wild bharals, accounting for more than $90 \%$ of the total gut microbiota. This result coincided with previous studies of the gut microbiota in other ruminants [24-27]. However, their abundances showed significant differences $(P<0.01)$ between groups. In ruminants, Firmicutes play an important role in fiber and cellulose degradation, and can degrade cellulose into volatile fatty acids, which can be used by the host [28]. Firmicutes and Bacteroidetes increase with increasing hay content in the food, and this characteristic of Firmicutes is particularly prominent [29]. Although wild bharals have access to a wide variety of food sources, due to the harshness of the environment in winter, they mainly feed on grasses with high fibre content. Compared to captive bharals, wild bharals showed a higher abundance of Firmicutes, which leads to improved digestion and absorption of nutrients. Bacteroides can promote digestion, decompose polysaccharides and proteins, improve the utilization rate of assimilated nutrients [30,31], and maintain the balance of intestinal microecological system [32]. The diet of captive bharals consists of semi-dried oat grass (Arrhenatherum elatius), 


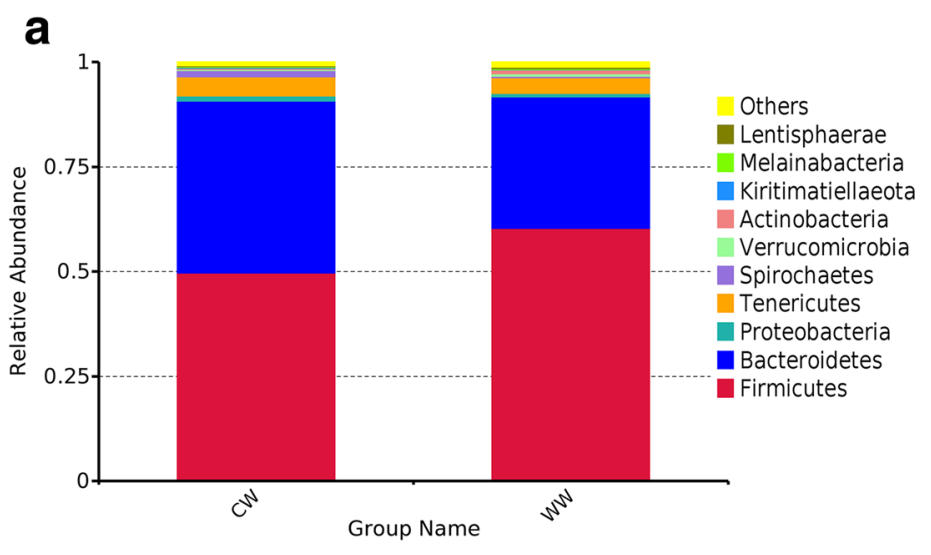

b

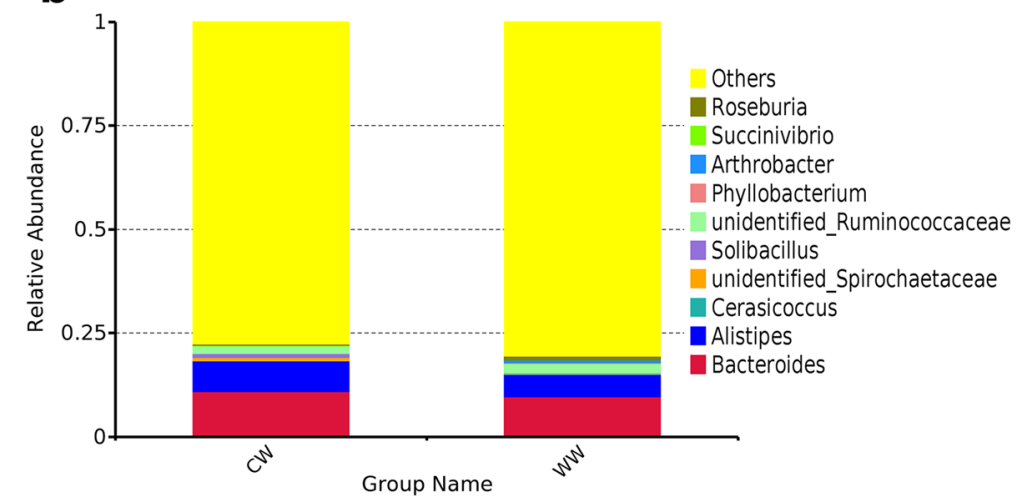

Fig. 2 Relative abundance histogram. Fecal microbial composition of wild (WW) and captive (CW) bharals at the phylum (a) and genus (b) level. Each bar represents the top ten bacterial species ranked by the relative abundance in each group

carrot (Daucus carota), and artificial fodder. The utilized recipes are simple in structure; however, the protein, polysaccharide, and fat contents of the artificial fodder are relatively high. This might be the reason for the higher abundance of Bacteroides in the intestinal flora of captive bharals compared to wild bharals.

LEfSe analysis showed a number of bacteria that play an important role in metabolism of nutrients and the health of the host. Previous studies have reported that Alistipes shows a correlation with metabolites such as short-chain fatty acids, oligosaccharides, and amino acids. Lachnospiraceae and Ruminococcaceae belong to butyrate-producing bacteria. These bacteria and metabolites exert an important impact on host health [33, 34].

In addition, the Alpha-diversity of the captive group was significantly lower than that of the wild group. The food sources accessible to wild animals are more diverse, thus providing bharals with many different types of nutrition, which may require a more diversified gut microbiota to help bharals complete digestion and utilization of these nutrients [35, 36].

Further research has shown that many chronic diseases are caused by a decrease in the diversity of gut microbiota, including inflammatory gut disease and diabetes [37]. Comparison of the inter-group differences of the intestinal flora showed that the relative abundances of Spirochaetes $(P<0.01)$, Acidobacteria $(P<0.01)$ and Gemmatimonadetes $(P<0.01)$ in the captive group were significantly higher than in the wild group; these bacteria showed a certain pathogenicity [38, 39]. However, Ruminococcaceae, Lachnospiraceae, and Christensenellaceae in the captive group were significantly lower than in the wild group; these bacteria are beneficial microbiota in the host intestines [40]. These results suggest that captive bharals may face a higher risk to catch diseases than wild bharals.

This relationship between gut microbiota and host health, and in particular, the impact of microbial dissonance on host health, indicates the importance of feasible strategies to optimize the gut microbiota via diet. This means that diseases caused by changes in the gut microbiome can be regulated through the diet of the host. Food types can be reasonably chosen, a number of nutrients can be appropriately supplemented, and the healthy development of gut microbiota can be promoted. This will be conducive to the protection of wildlife ex situ. 


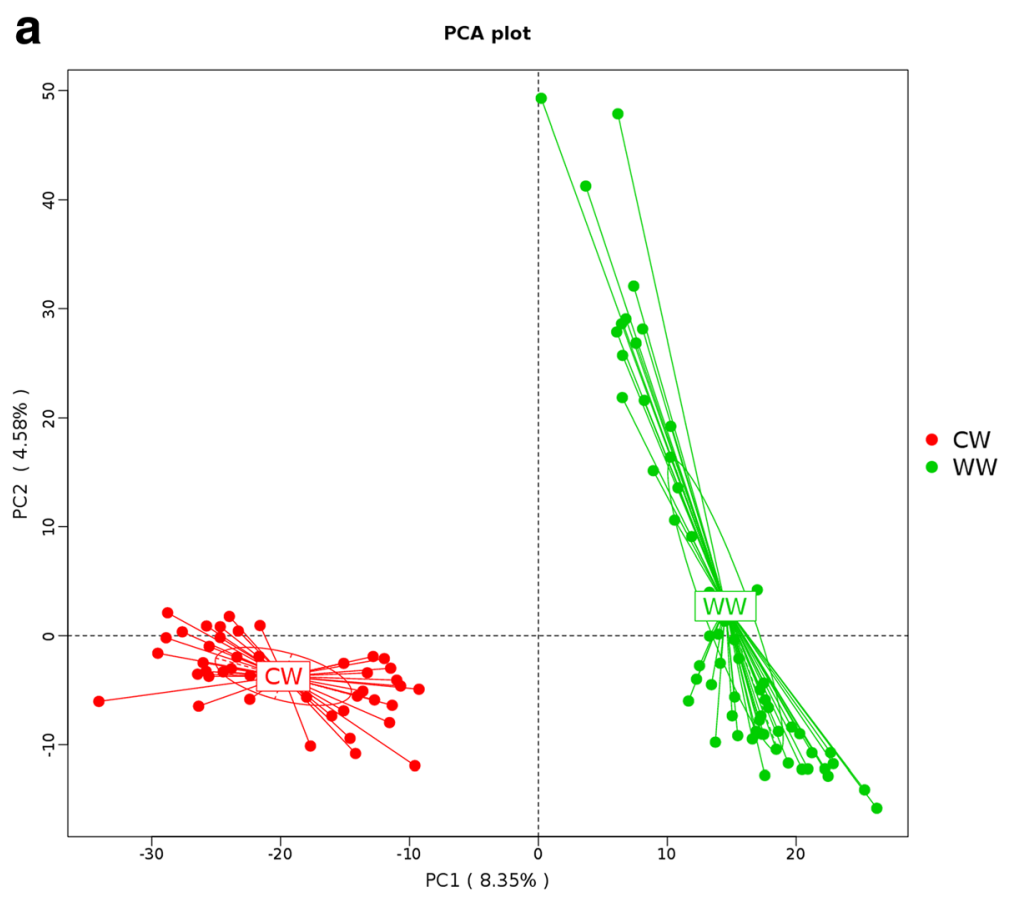

b

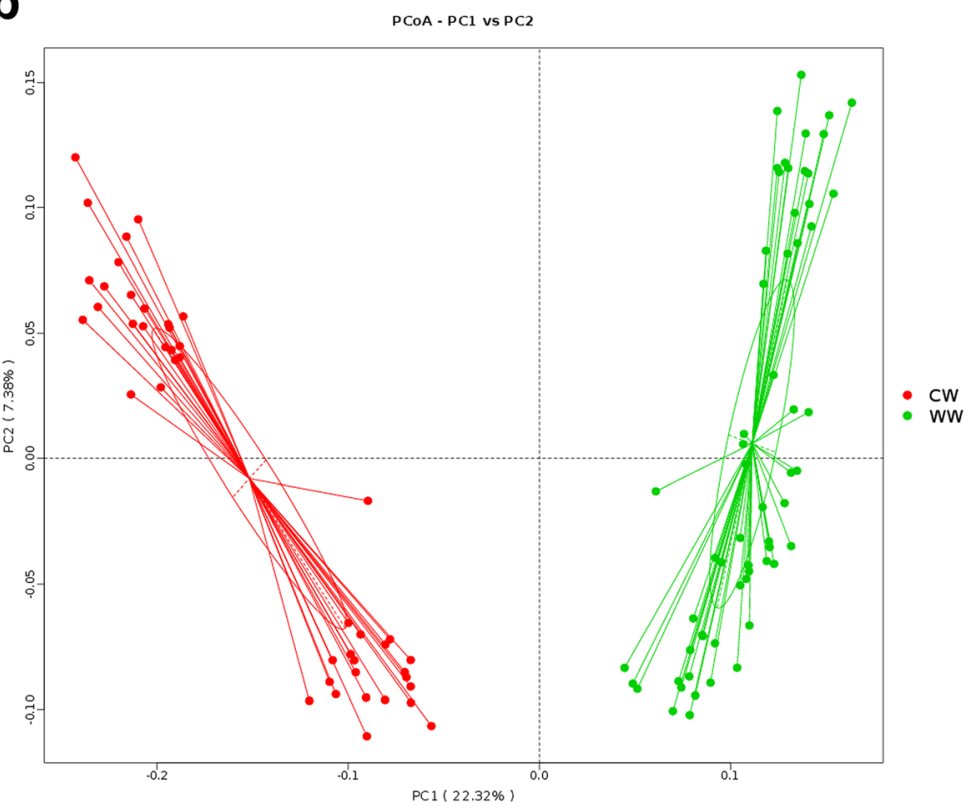

Fig. 3 PCA (a) and PCOA (b) plot of the bacterial population structures. The green and red dots represented wild (WW) and captive (CW) bharals samples respectively

\section{Conclusion}

This study described and compared the gut microbiota of wild and captive bharals and significant differences were found between both groups. The difference in diet may have caused a decrease of gut microbiotic diversity and an increase of relative abundance of pathogenic bacteria. The result would be an increased susceptibility to diseases in captive bharals, which is extremely unfavorable for their protection. These findings provide further research directions for the study of the effect of gut microbiota on the growth and development of bharals. Moreover, this study provides theoretical guidance for the diagnosis and detection of intestinal diseases in bharals, and can also be used as a reasonable and balanced reference for the diet of captive bharals. The findings provide a theoretical basis for the screening 


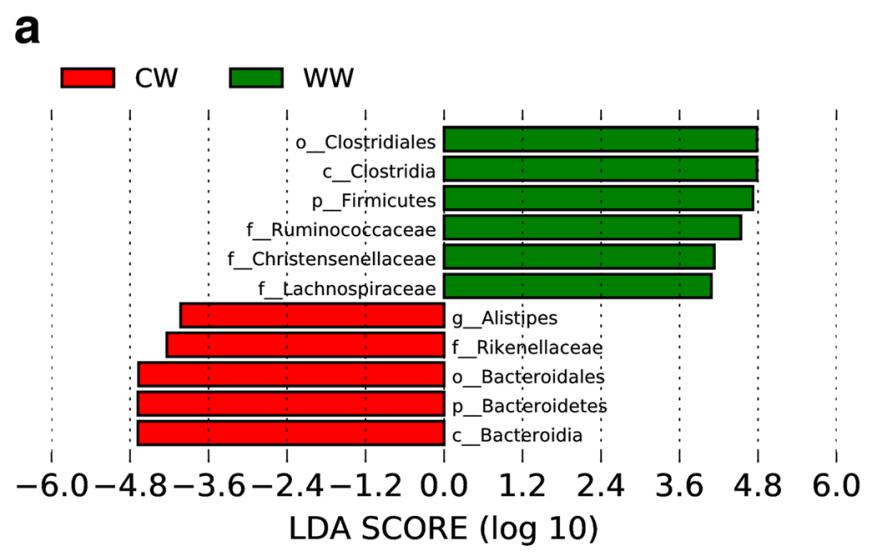

b

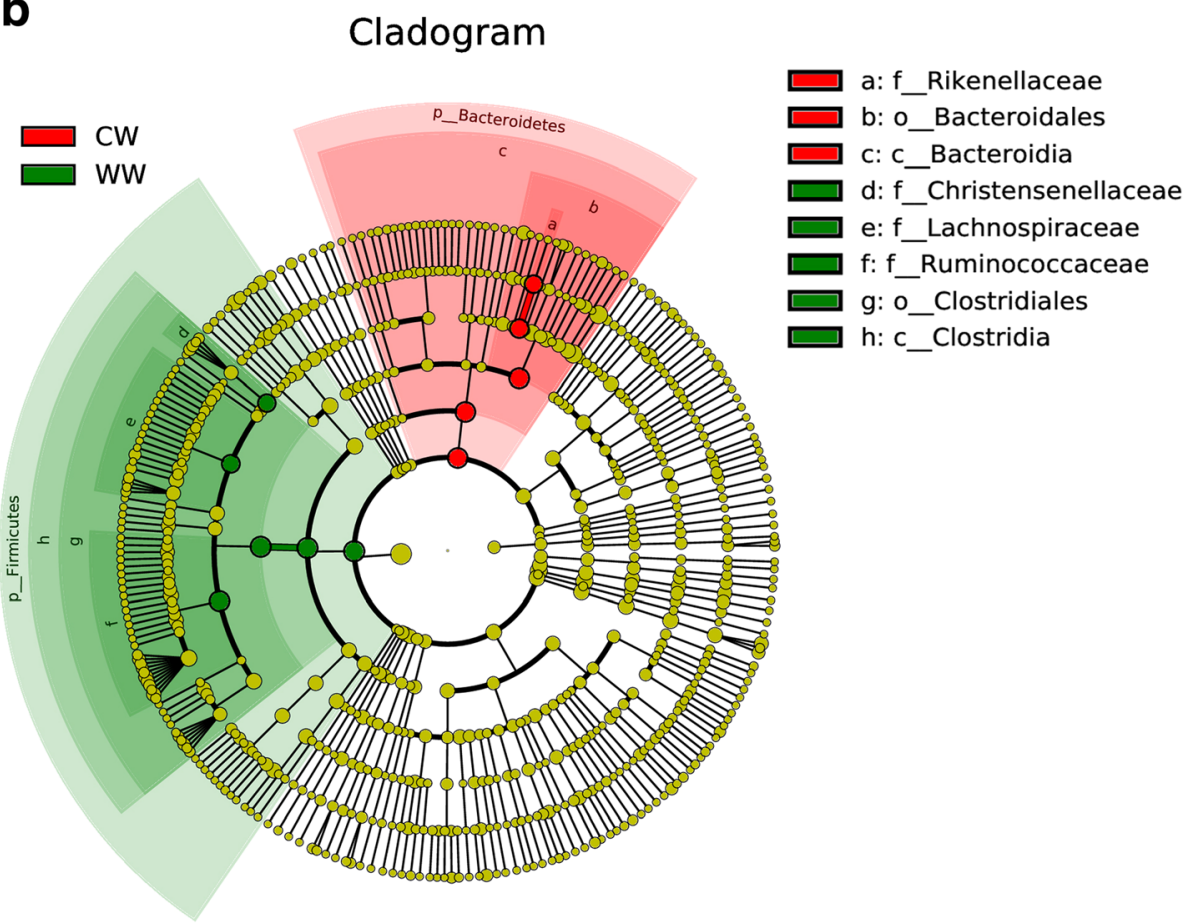

Fig. 4 The results of LEfSe (LDA Effect Size) analysis. The histogram of LDA score(a) showed the biomarkers with significant differences between groups. The length of the column (LDA Score) represents the influencing degree of biomarkers, In the cladogram(b), the circle radiated inside-out represented the classification of phylum to genus level. Each small circle at different classification levels represented a taxon and the diameter of small circle is proportional to the relative abundance. The species not with significant differences were colored by yellow and biomarkers were colored by different groups. CW for captive group, WW for wild group

of probiotics and development of intestinal microecological agents.

\section{Methods}

\section{Feces samples collection}

The difficulties of wildlife sampling and the religious beliefs of ethnic minorities are considered, feces samples were selected as test material in this study. At present, most of the research on wildlife in this aspect takes fecal samples as research objects, the results describe the structure of the gut microbiota of bharals. Therefore, during
January 2018, a total of 240 fresh feces samples of wild bharals were collected from different regions near the Donggeicuona Lake in Maduo County, Qing Hai, China. The average temperature of Maduo in January is $-16.8^{\circ} \mathrm{C}$, which retained the freshness of the feces of wild bharals as much as possible. The collected samples were temporarily stored in an in-vehicle refrigerator $\left(-20^{\circ} \mathrm{C}\right)$.

Forty-four fresh feces samples were collected from 11 bharals in captivity at the Qinghai-Tibet Plateau Wildlife Zoo during December 2017. To prevent sample contamination, the bharals enclosure was cleaned in advance 
and none of the sample donors received antibiotic or probiotic therapy for the past three months. The collected samples were temporarily stored in dry ice ($50^{\circ} \mathrm{C}$ ). All feces samples were eventually frozen and stored at $-80^{\circ} \mathrm{C}$ for further analyses.

\section{DNA extraction}

Total genome DNA of samples was extracted by CTAB method using QIAamp Stool Mini Kit (Qiagen, Germany). DNA concentration and purity were detected with $1 \%$ agarose gel. Diluted the DNA to $1 \mathrm{ng} / \mu \mathrm{L}$ with sterile water.

\section{PCR amplification, purification and sequencing}

$16 \mathrm{~S}$ rRNA genes of distinct regions (V4-V5) were amplified used specific primer (515F:5'-GTGCCAGCMGCCGCGGTAA-3'; 907R:5'-CCGTCAATTCCTTTGAGTTT-3') with the barcode [41]. All PCR reactions were $30 \mu \mathrm{L}$ systems, including $15 \mu \mathrm{L}$ Phusion High-Fidelity PCR Master Mix (New England Biolabs), $3 \mu \mathrm{L}(2 \mu \mathrm{M})$ forward and reverse primers, $10 \mu \mathrm{L}(10 \mathrm{ng})$ template DNA and $2 \mu \mathrm{L} \mathrm{dd}_{2} \mathrm{O}$. The thermal cycling consisted of pre-denatured at $98^{\circ} \mathrm{C}$ for $1 \mathrm{~min}$, followed by 30 cycles, including denaturation at $98^{\circ} \mathrm{C}$ for $10 \mathrm{~s}$, annealing at $50^{\circ} \mathrm{C}$ for $30 \mathrm{~s}$, and extension at $72{ }^{\circ} \mathrm{C}$ for $30 \mathrm{~s}$. Finally, $72{ }^{\circ} \mathrm{C}$ for $5 \mathrm{~min}$.

The $1 \times$ loading buffer (contained SYB green) of the same volume was mixed with the PCR products and detected by $2 \%$ agarose gel electrophoresis. PCR products was mixed in equidensity ratios. Then, mixture PCR products was purified with GeneJET ${ }^{\mathrm{mm}}$ Gel Extraction Kit (Thermo Scientific).

Sequencing libraries were generated using Ion Plus Fragment Library Kit 48 rxns (Thermo Scientific). The library was sequenced on an Ion $\mathrm{S} 5^{\mathrm{max}} \mathrm{XL}$ platform to produce $400 \mathrm{bp} / 600 \mathrm{bp}$ single-end reads.

\section{Sequence processing and statistical analysis}

Get single-end reads and filtered the quality of the raw reads to obtain high-quality clean reads [42] (V1.9.1, http://cutadapt.readthedocs.io/en/stable/). By using UCHIME algorithm (http://www.drive5.com/usearch/ manual/uchime_algo.html) [43], the reads were compared with the reference database to detect chimera sequences, and then removed [44]. Then the Clean Reads finally obtained. Sequences analysis were performed by Uparse software (Uparse v7.0.1001, http://drive5.com/ uparse/) [45]. Sequences with $\geq 97 \%$ similarity were assigned to the same operational taxonomic units (OTUs). Representative sequence for each OTU was screened for further annotation $[41,46]$.

Qiime software (Version 1.9.1) was used to analyze the differences of alpha diversity indexes between groups. $\mathrm{R}$ software (Version 2.15.3) was used to plot rarefaction curves, rank abundance curves, and stacked histograms of the relative abundance. Ade4 and ggplot2 packages in $\mathrm{R}$ were used for PCA and PCoA analyses, respectively. LEfSe software (LEfSe 1.0) was used for LEfSe analysis, which defaulted to a filter value of 4 for the LDA Score. For MRPP analysis, the MRPP function of the vegan package for $\mathrm{R}$ was used.

\section{Abbreviations}

LEfSe: Linear discriminant analysis coupled with effect size; MRPP: Multi Response Permutation Procedure; OTU: Operational taxonomic unit; PCA: Principal component analysis; PCoA: Principal co-ordinate analysis; PCR: Polymerase chain reaction; rRNA: Ribosomal ribonucleic acid

\section{Acknowledgements}

We would like to express our heartfelt thanks to the director of the YellowRiver-Sources Park Management Station in Three-River-Sources National Park of Mardo county and all bharals breeders at the Qinghai-Tibet Plateau Wildlife Zoo in Xining for their active cooperation and their valuable suggestions on the collection of bharals feces samples.

\section{Authors' contributions}

XWC, HMG, WQ, JRC, ZYC and TZZ contributed conception and design of the study; XWC, HMG, WQ, LW and JRC carried out the DNA extraction and data analysis; XWC, HMG, WQ, PFS, LW, and GSW participated in samples collection; HMG, GSW, WQ, PFS, LW and TZZ advised on manuscript content; XWC wrote the first draft of the manuscript. All authors read and approved the final manuscript.

\section{Funding}

This work was supported by following grants: National Key R\&D Program of China (2017YFC0506405) research design; The Strategic Priority Research Program of the Chinese Academy of Sciences (XDA23060602; XDA2002030302) data collection; Construction Fund for Qinghai Key Laboratories (2017-ZJ-Y23) data analysis and interpretation; Qinghai Key R\&D and Transformation Program (2019-SF-150) manuscript writing.

\section{Availability of data and materials}

The datasets generated and analysed during the current study are not publicly available due to further analysis at later stage, but are available from the corresponding author on reasonable request.

\section{Ethics approval and consent to participate}

All applicable international, national and institutional guidelines for animal care and use were observed. All procedures related to animal's research were approved by the Ethics and Welfare of Experiment Animals Committee affiliated to Northwest Institute of Plateau Biology.

\section{Consent for publication}

Not applicable.

\section{Competing interests}

The authors declare that they have no competing interests.

\section{Author details \\ ${ }^{1}$ Key Laboratory of Adaptation and Evolution of Plateau Biota, Northwest Institute of Plateau Biology, Chinese Academy of Sciences, No.23 Xinning road, Chengxi district, Xining TN 810008, Qinghai, China. ${ }^{2}$ University of Chinese Academy of Sciences, No.19 Yuquan road, Shijingshan district, Beijing TN 100049, China. ${ }^{3}$ Qinghai Provincial Key Laboratory of Animal Ecological Genomics, No.23 Xinning road, Chengxi district, Xining TN 810008, Qinghai, China. ${ }^{4}$ Qinghai-Tibet Plateau Wildlife Zoo, No.9 Xingzhi road, Chengxi district, Xining TN 810008, Qinghai, China.}

Received: 22 January 2019 Accepted: 4 July 2019 Published online: 12 July 2019

\section{References}

1. Thaiss CA, Zmora N, Levy M, Elinav E. The microbiome and innate immunity. Nature. 2016;535(7610):65-74.

2. Ley RE, Turnbaugh PJ, Klein S, Gordon Jl. Human gut microbes associated with obesity. Nature. 2006;444(7122):1022-3. 
3. Mølbak L, Johnsen K, Boye M, Jensen TK, Johansen M, Møller K, Leser TD. The microbiota of pigs influenced by diet texture and severity of Lawsonia intracellularis infection, Veterinary Microbiology. 2008:128(1-2):96-107.

4. Buddington RK, Sangild PT. COMPANION ANIMALS SYMPOSIUM: development of the mammalian gastrointestinal tract, the resident microbiota, and the role of diet in early life. J Anim Sci. 2011;89(5):1506-19.

5. Gillor O, Etzion A, Riley MA. The dual role of bacteriocins as anti- and probiotics. Appl Microbiol Biotechnol. 2008;81(4):591-606.

6. Schuijt TJ, van der Poll T, de Vos WM, Wiersinga WJ. The intestinal microbiota and host immune interactions in the critically ill. Trends Microbiol. 2013;21(5):221-9.

7. Koboziev I, Reinoso Webb C, Furr KL, Grisham MB. Role of the enteric microbiota in intestinal homeostasis and inflammation. Free Radic Biol Med. 2014:68:122-33.

8. Ley RE, Lozupone CA, Hamady M, Knight R, Gordon Jl. Worlds within worlds: evolution of the vertebrate gut microbiota. Nat Rev Microbiol. 2008; 6(10):776-88.

9. Schwab C, Cristescu B, Northrup JM, Stenhouse GB, Ganzle M. Diet and environment shape fecal bacterial microbiota composition and enteric pathogen load of grizzly bears. PLoS One. 2011;6(12):e27905.

10. Navarrete P, Magne F, Araneda C, Fuentes P, Barros L, Opazo R, Espejo R, Romero J. PCR-TTGE analysis of $16 \mathrm{~S}$ rRNA from rainbow trout (Oncorhynchus mykiss) gut microbiota reveals host-specific communities of active bacteria. PLoS One. 2012;7(2):e31335.

11. Kovács F, Nagy B, Sinkovics G. The gut bacterial flora of healthy early weaned piglets, with special regard to factors influencing its composition. Acta Vet Acad Sci Hung. 1972;22(4):327.

12. McKenney PT, Pamer EG. From hype to Hope: the gut microbiota in enteric infectious disease. Cell. 2015;163(6):1326-32.

13. Cox LA, Olivier M, Spradlingreeves K, Karere GM, Comuzzie AG, Vandeberg J. Nonhuman Primates and translational research-cardiovascular disease. ILAR J. 2017;58(2):235-50

14. Wang XM, Li M, Tang S, Liu Z. A preliminary study of some characters of blue sheep population ecology in spring. Acta Theriologica Sinica. 1998; 18(1):27-33.

15. Schaller GB. Mountain monarchs. wild sheep and goats of the Himalaya. Chicago: University of Chicago Press; 1977. p. 425.

16. Wang XM, Schaller GB. Status of Large Mammals in Western Inner Mongolia, China. Journal of East China Normal University (Special Issue of Mammals). 1996;6:93-104

17. Schaller GB. Wildlife of the Tibetan steppe, vol. 373. Chicago: University of Chicago Press; 1998.

18. Liu CG, Zhang SW, Ren JR. Research foods and foods source about snow leopard(Panthera uncia). Journal of Shaanxi No rmal University (Natural Science Edition). 2003;31(S2):154-9.

19. Cheng $X$, Yin $X$, Xia G, Yu Y, Hou X. Analysis of age structure of blue sheep population. Shaanxi Journal of Agricultural Sciences. 2014;60(08):40-2.

20. Liu ZS, Wang XM, Li ZG, Cui DY, Li XQ. Seasonal variation of diurnal activity budgets by blue sheep (Pseudois nayaur) with different age-sex classes in Helan Mountain. Zool Res. 2005:26(4):350-7.

21. Zhu M, Zhou C, He Y, Huang Y, Lu D, Zeng X. Exploring the phylogenetic relationships among species of tribe caprini based on mitochondrial Cyt b and nuclear gene ZFY. Acta Theriologica Sinica. 2014;34(4):366-73.

22. Cao LR, Wang XM, Fang SG. A molecular phylogeny of Bharal and dwarf blue sheep based on mitochondrial cytochrome $b$ gene sequences. Acta Zool Sin. 2003:49(2):198-204.

23. Lundberg DS, Yourstone S, Mieczkowski P, Jones CD, Dangl JL. Practical innovations for high-throughput amplicon sequencing. Nat Methods. 2013; 10(10):999-1002

24. Sundset MA, Praesteng KE, Cann IK, Mathiesen SD, Mackie RI. Novel rumen bacterial diversity in two geographically separated sub-species of reindeer Microb Ecol. 2007;54(3):424-38.

25. Gruninger RJ, Sensen CW, McAllister TA, Forster RJ. Diversity of rumen bacteria in Canadian cervids. PLoS One. 2014;9(2):e89682.

26. Ishaq SL, Wright AD. High-throughput DNA sequencing of the ruminal bacteria from moose (Alces alces) in Vermont, Alaska, and Norway. Microb Ecol. 2014;68(2):185-95.

27. Koike S, Yoshitani S, Kobayashi Y, Tanaka K. Phylogenetic analysis of fiberassociated rumen bacterial community and PCR detection of uncultured bacteria. FEMS Microbiol Lett. 2003;229(1):23-30.

28. Thoetkiattikul H, Mhuantong W, Laothanachareon T, Tangphatsornruang S, Pattarajinda V, Eurwilaichitr L, Champreda V. Comparative analysis of microbial profiles in cow rumen fed with different dietary fiber by tagged 16S rRNA gene pyrosequencing. Curr Microbiol. 2013;67(2):130-7.

29. Chen Y, Penner GB, Li M, Oba M, Guan LL. Changes in bacterial diversity associated with epithelial tissue in the beef cow rumen during the transition to a high-grain diet. Appl Environ Microbiol. 2011;77(16):5770-81.

30. Spence C, Wells WG, Smith CJ. Characterization of the primary starch utilization operon in the obligate anaerobe Bacteroides fragilis: regulation by carbon source and oxygen. J Bacteriol. 2006;188(13):4663-72.

31. Backhed F, Ding H, Wang T, Hooper LV, Koh GY, Nagy A, Semenkovich CF, Gordon J. The gut microbiota as an environmental factor that regulates fat storage. Proc Natl Acad Sci U S A. 2004;101(44):15718-23.

32. Sears CL. A dynamic partnership: celebrating our gut flora. Anaerobe. 2005; 11(5):247-51.

33. Zhao Y. Study on the correlation between antibiotic induced changes in mouse flora and host metabolism: Doctoral dissertation. Huazhong university of science and technology; 2013.

34. Kang C, Hui SC, Zhu XH, Mi MT: Study on the mechanism of intestinal flora in capsaicin improving the signs of obesity induced by high-fat diet in mice. In: The 13th western China nutrition and health summit BBS: 2018; Chengdu, sichuan, China; 2018: 1.

35. Bourquin LD, Titgemeyer EC, Fahey GC Jr. Vegetable fiber fermentation by human fecal bacteria: cell wall polysaccharide disappearance and shortchain fatty acid production during in vitro fermentation and water-holding capacity of unfermented residues. J Nutr. 1993;123(5):860-9.

36. Bourquin LD, Titgemeyer EC, Fahey GC. Fermentation of various dietary fiber sources by human fecal bacteria. Nutr Res. 1996;16(7):1119-31.

37. Bolnick DI, Snowberg LK, Hirsch PE, Lauber CL, Org E, Parks B, Lusis AJ, Knight R, Caporaso JG, Svanbäck R. Individual diet has sex-dependent effects on vertebrate gut microbiota. Nat Commun. 2015;5:4500.

38. Konturek PC, Haziri D, Brzozowski T, Hess T, Heyman S, Kwiecien S, Konturek SJ, Koziel J. Emerging role of fecal microbiota therapy in the treatment of gastrointestinal and extra-gastrointestinal diseases. J Physiol Pharmacol. 2015;66(4):483-91.

39. Rieger MA, Parlesak A, Pool-Zobel BL, Rechkemmer G, Bode C. A diet high in fat and meat but low in dietary fibre increases the genotoxic potential of 'faecal water'. Carcinogenesis. 1999;20(12):2311-6.

40. Zhang $Y$ : Antibiotics-induced mice microbial alteration and their relationship with host metabolic profiles. Master's thesis. Shandong Normal University; 2018

41. Luo M, Liu Y, Wu P, Luo DX, Sun Q, Zheng H, Hu R, Pandol SJ, Li QF, Han YP. Alternation of gut microbiota in patients with pulmonary tuberculosis. Front Physiol. 2017;8(822).

42. Martin M. Cutadapt removes adapter sequences from high-throughput sequencing reads. Embnet Journal. 2011;17(1).

43. Edgar RC, Haas BJ, Clemente JC, Quince C, Knight R. UCHIME improves sensitivity and speed of chimera detection. Bioinformatics. 2011;27(16):2194-200.

44. Haas BJ, Gevers D, Earl AM, Feldgarden M, Ward DV, Giannoukos G, Ciulla D, Tabbaa D, Highlander SK, Sodergren E, et al. Chimeric 165 rRNA sequence formation and detection in sanger and 454-pyrosequenced PCR amplicons. Genome Res. 2011;21(3):494-504.

45. Edgar RC. UPARSE: highly accurate OTU sequences from microbial amplicon reads. Nat Methods. 2013;10(10):996-8.

46. Bokulich NA, Subramanian S, Faith JJ, Gevers D, Gordon Jl, Knight R, Mills DA, Caporaso JG. Quality-filtering vastly improves diversity estimates from Illumina amplicon sequencing. Nat Methods. 2013;10(1):57-9.

\section{Publisher's Note}

Springer Nature remains neutral with regard to jurisdictional claims in published maps and institutional affiliations. 